\title{
Study on Occupational Radiation Exposure at Different Hospitals in Nepal using Thermoluminescence Dosimetry
}

\author{
Prabhash Acharya ${ }^{1}$, Gita Chalise ${ }^{2}$, Bipin Rijal ${ }^{1}$,Hari Prasad Lamichhane ${ }^{2}$, \\ Buddha Ram Shah ${ }^{1 *}$ \\ ${ }^{1}$ Physical Science Laboratory, \\ Nepal Academy of Science and Technology, Khumaltar, Lalitpur \\ ${ }^{2}$ Central Department of Physics, Tribhuvan University, Kritipur, Kathmandu
}

*Corresponding Author

buddharshah25@gmail.com; buddharam.shah@nast.gov.np

\begin{abstract}
The clinical efficacy of using ionizing radiation in diagnosis and treatment of diseases has been revolutionized, benefitting humankind and, at the same time, imposing deleterious health effects, if not handled carefully. Personnel dosimetry has emerged as an essential tool to monitor occupational radiation exposure. The present study intends to reveal and describe the scenario of occupationally exposed staff by assessing an individual'sdose in radiological facilities at different hospitals in Nepal. Thermoluminescent Dosimetry (TLD) has been used for assessing individual doses. Altogether eight hospitals were chosen from different locations of Nepal. TLD badges were worn by the radiation workers on their chest level while working with the radiological equipment for about three to ten months during their routine work. Later the badges were read out in the TLD badge reader system available at Nepal Academy of Science and Technology (NAST) to obtain the exposed doses. CaSO4: Dy was used as TL phosphor. Exposed doses for health personnel during their routine work were foundin the range of (2.21 to 16.17$) \pm 0.01 \mathrm{mSv}$ per year, which was low compared to the permissible dose limit of $20 \mathrm{mSv}$ per year set up by International Commission on Radiological Protection(ICRP). Although the exposed dose rates in the monitored hospitals are below the recommended dose limits, it should be made as low as possible based on the ALARA principle.
\end{abstract}

\section{Keywords}

Dosimeter, exposure, ionizing radiation, radiation protection, TLD

\section{Introduction}

Radiation, which is used extensively to diagnose and treat human disease, possesses an occupational health risk, and if the exposure is higher than the threshold value, it could have deleterious health effects. Given the effects that radiation exposure can lead to, there is a clear need to have a system that affords appropriate levels of radiation protection in a situation where radiation is being used (Aschan 1999). For artificial sources of radiation, the medical sector is dominating the global occupational collective dose (Bhatt and Kulkarni 2013). Monitoring individual radiation workers is an essential and regulatory requirement for the surveillance of radiation workers in diagnostic and interventional radiology, nuclear medicine, and radiation therapy. It allows the individual to get acquainted with whether the possible absorbed dose they are receiving is within the limit as set by ICRP recommendations or not and whether protective ambiance could render safe and practicable services to patients (Gautam and Prashain 2011).

Although a National Nuclear Policy and Nuclear Materials Regulatory Directive have been issued, the Radiation Regulatory body has not yet been formed in the absence of the Nuclear Law of the country (National Nuclear Policy 2007; Nuclear Materials Regulatory Directive 2015). Since Nepal became a member state of the 
International Atomic Energy Agency (IAEA) in 2008, the formulation of Nuclear Law has been accelerated and is in the process of endorsement by the Parliament. Under the Basic Safety Series of IAEA, the GSR Part 3 and 7 are essential for the effectiveness of developing radiation safety culture (IAEA GSR Part 7 2015/IAEA GSR Part 3 2014). General data, particularly about the diagnostic radiology, nuclear medicine, and radiotherapy service, are limited, and the situation regarding shielding and personnel dosimetry is unclear (Bhatt et al., 2012; Khanal et al., 2014).

In such a background, this study aimed to reveal the existing practice of personal ; dosimetry in Nepal and to focus on the necessity of personnel monitoring using Thermoluminescent Dosimeter (TLD) in all possible hospitals throughout Nepal. In the Asia and Pacific region, IAEA/ ARPANSA intercomparison exercise on wholebody dosimeters has shown that the majority of the individual monitoring service (IMS) are using solid-state dosimeters TLD [Rizk et al., 2019]. The study, however, was limited to a few hospitals regarding the availability of TLD cards.

\section{Methodology}

Of the various techniques that can be used for the estimation of the doses of ionizing radiation, thermoluminescence dosimetry has been used for the absorbed dose estimation of irradiated TLD badges because of the convenience of batch evaluation, reusability, broad detection range, linearity, and cost-effectiveness (Aschan 1999; Bhatt and Kulkarni 2014; Rizk et al., 2019). It primarily consists of two major parts: TLD badge and the TLD badge reader.

The TLD badge (type: TL 1010A) comprises of a plastic cassette containing three Teflon TLD discs (13.3mm and $0.8 \mathrm{~mm}$ thick) that are mechanically clipped onto circular holes $(12.0 \mathrm{~mm})$ punched in an aluminum card (52x30x1mm). This TL disc contains CaSO4: Dy as TL phosphor (BARC 1986), as shown in Fig.1. On the other hand, the TLD badge reader (Nucleonix, India) incorporates a semi-automatic mechanical arrangement that comprises microcontroller-based electronic control circuits, card transport mechanism, PMT housing, gas heater, temperature control circuit wherein the TLD cards are read (Nucleonix 2013) as shown in Fig.2.

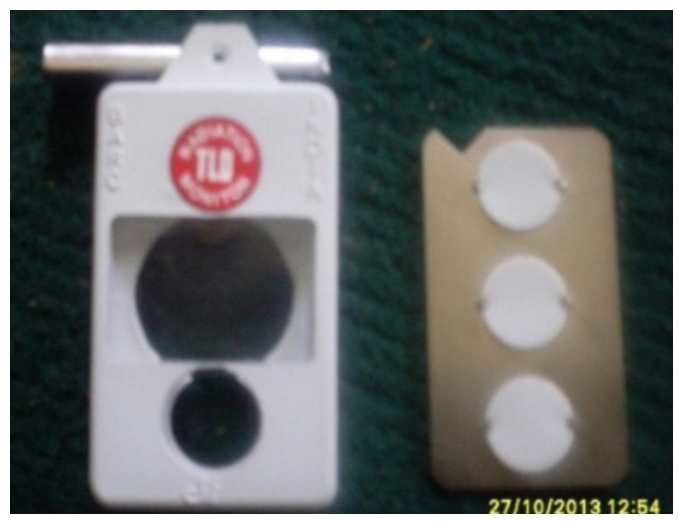

Fig.1. TLD badge

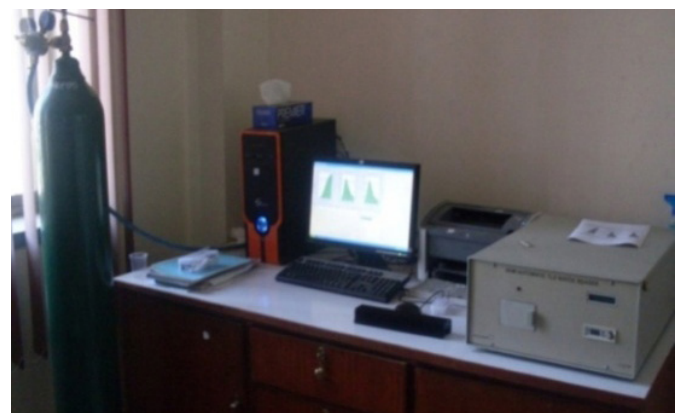

Fig.2 TLD reader along with $\mathrm{N}_{2}$ cylinder and personal computer with glow curve on its monitor

In order to recover original TLD sensitivity of the irradiation and readout, all cards were subjected to an annealing treatment at an elevated temperature of about 300 degree Celsius for 3 hours before their us in an annealing oven (Furetta 2003; Shrivastava et al., 2011, Lakshmanan 2008) as given in Fig.3.

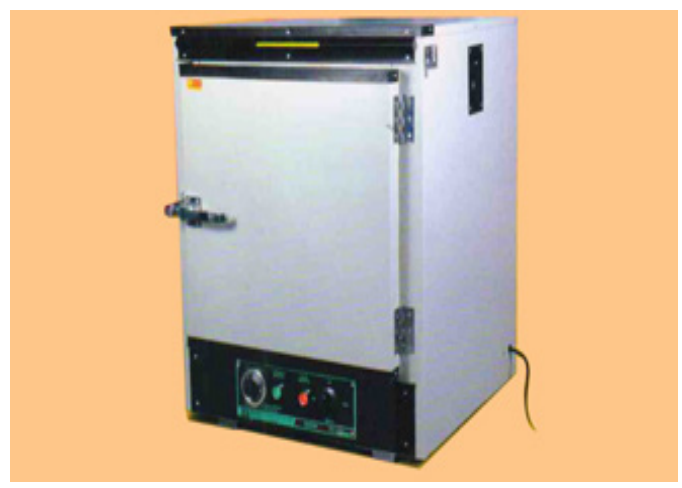

Fig.3. Annealing Oven

Also, calibration of the badge reader and quality 
Table 1. List of Hospitals, Working Area and Exposure Duration

\begin{tabular}{|c|c|c|c|c|c|}
\hline S.N & Name of Hospital & Location & Working Area & $\begin{array}{l}\text { No. of radiation } \\
\text { workers }\end{array}$ & $\begin{array}{l}\text { Duration } \\
\text { (months) }\end{array}$ \\
\hline \multirow[t]{2}{*}{1} & \multirow[t]{2}{*}{ Om Hospital and Research Centre } & \multirow[t]{2}{*}{ Chabahil } & CT Scan & 2 & \\
\hline & & & General X-ray & 3 & 3 \\
\hline \multirow[t]{2}{*}{2} & \multirow[t]{2}{*}{ SahidGangalal Cardiac Centre } & \multirow[t]{2}{*}{ Baansbari } & General X-ray & 2 & \multirow[t]{2}{*}{3} \\
\hline & & & Cath lab & 2 & \\
\hline 3 & BP Smriti Hospital & Basundhara & General X-ray & 5 & 3 \\
\hline 4 & Patan Academy of Health Sciences & Lagankhel & General X-ray & 4 & 3 \\
\hline 5 & Green City Hospital & Dhapasi & General X-ray & 3 & 3 \\
\hline 6 & Gandaki Zonal Hospital & Pokhara & General X-ray & 4 & 3 \\
\hline 7 & Koshi Zonal Hospital & Biratnagar & General X-ray & 2 & 3 \\
\hline \multirow[t]{5}{*}{8} & \multirow{5}{*}{$\begin{array}{l}\text { Tribhuvan University Teaching } \\
\text { Hospital }\end{array}$} & \multirow{5}{*}{$\begin{array}{l}\text { Maharaj- } \\
\text { gunj }\end{array}$} & General X-ray & 2 & \multirow{5}{*}{10} \\
\hline & & & CT Scan & 2 & \\
\hline & & & $\begin{array}{l}\text { Mammogra- } \\
\text { phy }\end{array}$ & 1 & \\
\hline & & & C-Arm & 1 & \\
\hline & & & Fluoroscopy & 2 & \\
\hline
\end{tabular}

assurance program of individual monitoring service is necessary for the reliability of obtained results as well as to meet international standards (Srivastava 2016). As a part of the calibration technique, nine of the annealed TLD cards were directly exposed from Cobalt 60 source, maintaining the distance between Cobalt source and horizontally placed TLD card equal to $80 \mathrm{~cm}$. These exposed TLD cards were then processed for data acquisition (absorbed doses) into the badge reader using the software package (TL Badge Reader Nucleonix) developed for it. The area under the glow curve gives the measurement of equivalent absorbed dose.

Other annealed thermoluminescent badges were distributed to selective two to eight radiation workers to be worn while performing their routine works for specific time duration at seven different hospitals, as shown in table 1 .

\section{Results}

The calibration process was carried out to find the calibration factor $(\mathrm{m})$ defined as ratio of the measured (absorbed) value of dose by TLD reader divided by that value of the directly exposed dose, which is shown in table 2. The calibration factor was found to be 0.71 .

Also, the correlation coefficient between the observed dose in TLD reader and the known exposed value was 0.98 , which showed a high positive correlation between them verifying the reliability of the readings from TLD reader. The Calibration curve for the TLD Reader is as shown in Fig.4.

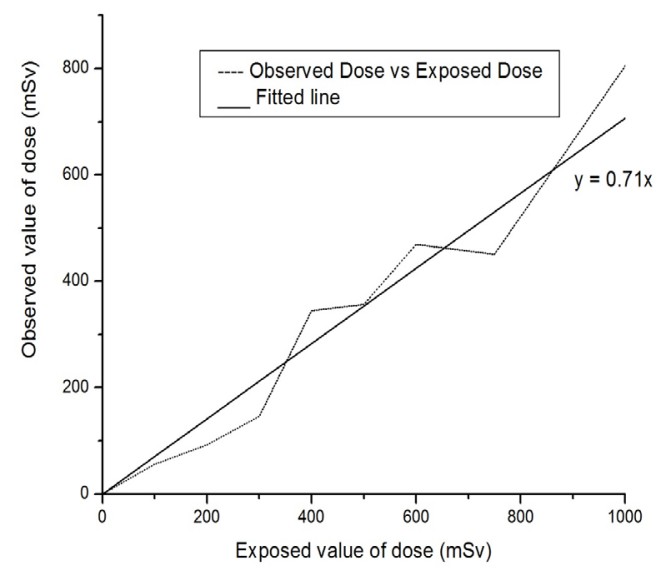

Fig.4. Calibration Curve for TLD Reader

All the TLD cards used by different health workers at different hospitals for three months 
Nepal Journal of Science and Technology (NJST) (2020), 19(1)

Table 2. Calculation of estimated dose and calibration factor(m)

\begin{tabular}{|c|c|c|c|}
\hline $\begin{array}{c}\text { Serial } \\
\text { Number for } \\
\text { cards }\end{array}$ & Exposed dose in $\mathrm{mSv}(\mathrm{x})$ & Observed dose in $\mathrm{mSv}\left(\mathrm{y}_{\mathrm{obs}}\right)$ & $\begin{array}{l}\text { Estimated dose in } \\
\mathrm{mSv}_{\mathrm{y}_{\text {east }}}=\mathbf{m x}\end{array}$ \\
\hline 1 & 0 & 0.06 & 0 \\
\hline 2 & 100 & 56.02 & 71 \\
\hline 3 & 200 & 92.54 & 142 \\
\hline 4 & 300 & 145.79 & 213 \\
\hline 5 & 400 & 344.47 & 284 \\
\hline 6 & 500 & 356.99 & 355 \\
\hline 7 & 600 & 469.35 & 426 \\
\hline 8 & 750 & 450.58 & 532.50 \\
\hline 9 & 1000 & 805.04 & 710 \\
\hline $\mathrm{m}=0.71$ & & & \\
\hline
\end{tabular}

and ten months period were read out and finally absorbed dose rate for each radiation worker, and the corresponding dose rate to which one would be exposed for one year was calculated. The absorbed dose rates were divided by the calibration factor to obtain the exact exposure rates of the personnel.

The exposed doses obtained after the badge analysis rates for health personnel at respective hospitals is shown in Fig.5.

\section{Discussion}

The exposure of an individual was found in the range of (2.21-16.17) $\pm 0.01 \mathrm{mSv}$ per year. This variation of dose rates in different hospitals showed that staff of hospitals with comparatively large value are likely to be susceptible to radiation hazards though they are still under the permissible limits of $20 \mathrm{mSv}$ per annum as set by the ICRP (ICRP publication 103 2007). For the procedures

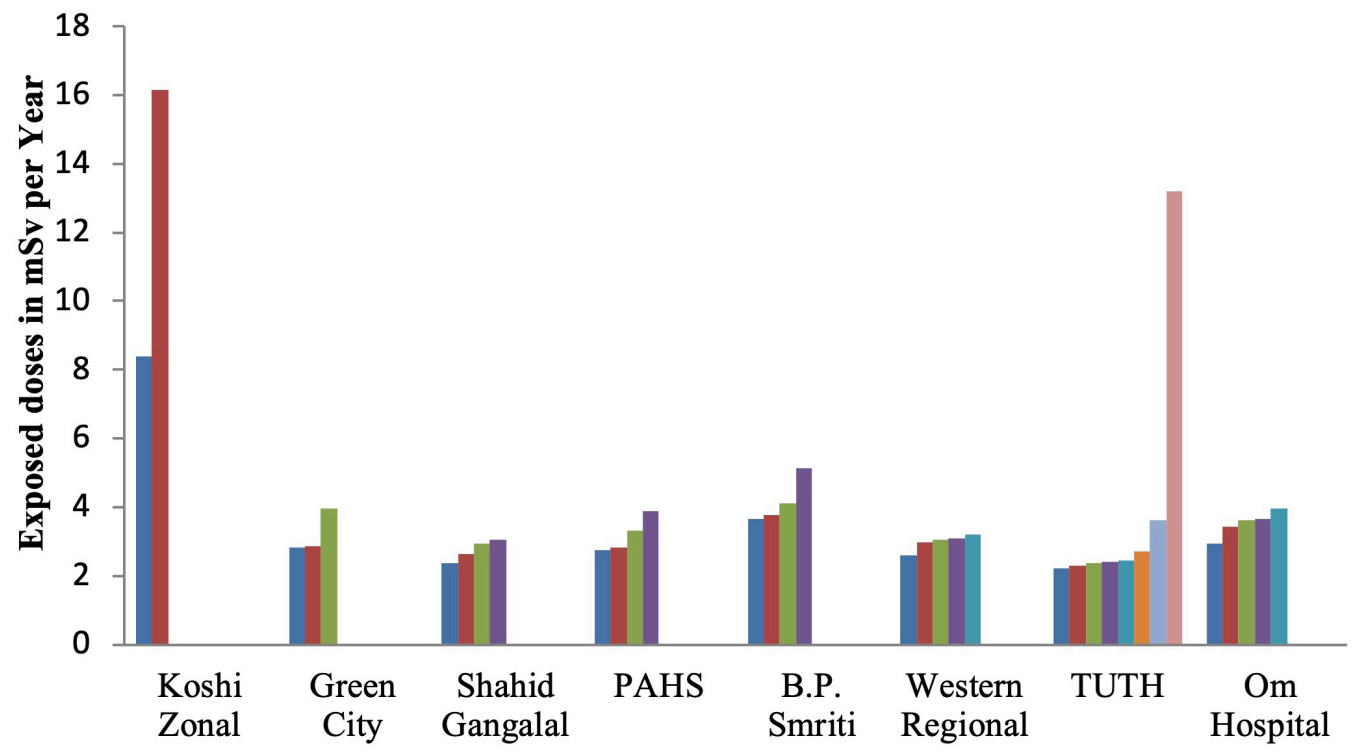

Personnel of Hospitals

Fig.5. Individual Exposure Dose 
like general X-ray, CT scan, and mammography where the radiation workers don't have to get direct radiation exposure, the primary exposure, if any, would be because of improper shielding of door and window or any random accidental error. In the monitoring of individuals at eight hospitals (Fig.5, Table 1) during 3 to 10 months, personnel of fluoroscopy and interventional procedures received comparatively higher doses than general X-ray and CT scan except at Koshi Zonal hospital, where general diagnostic X-ray personnel received higher doses. The use of lead aprons, thyroid shields, and gloves should be mademandatory for workers working in high exposure environments such as fluoroscopy and other interventional procedures.If minimum exposure in one hospital is possible, it should be made possible on all other hospitals either by reducing working hours of health workers or by focusing on appropriate distance and shielding rules. According to inverse square law for radiation, the dose absorbed by the body is inversely proportional to the square of the distance of a body from the source exposing to radiation. Shielding should be proper, for that walls, ceilings within which radiation is used for medical practices should have an appropriate thickness, ensuring the impenetrability of scattered radiation through them (IAEA Specific Safety Guide 2011).

The annual exposure to radiation depends on several factors within the workplace, which include types of radiological facilities, distribution of workload among workers, and radiation safety practices. The effects of these factors on occupational exposure are not evaluated in this study.

\section{Conclusion}

In general, the occupationally exposed individualprofile in different hospitals indicated insignificant overall health hazards; however, there is still a need for proactive preventive measures because low dose radiations can have cumulative hazardous effects with time. For this, personnel dosimetry is imperative in hospitals regularly as it verifies the effectiveness of radiation safety practices in the workplace by identifying working practices that minimize doses and provide information in the event of accidental exposure in compliances of GSR Part 3 and
GSR Part 7 of IAEA. Above all, there should be National Radiation Protection Authority as well as a medical physicist in each hospital to regulate and to ensure the safe radiation practices.

\section{Acknowledgment}

PA and GC would like to acknowledge the Nepal Academy of Science and Technology (NAST) for providing instruments and lab facilities to conduct this work. The authors are thankful to all the hospitals and individuals for their continuous cooperation throughout the monitoring.

\section{References}

Aschan, C.1999.Applicability of thermoluminescent dosimeters in $\mathrm{x}$-ray organ dose determination and the dosimetry of systematic and boron neutron capture radiotherapy. Academic dissertation.Department of Physics, University of Helsinki,Finland.

Bhatt, B.C., and M.S.Kulkarni.2013. Worldwide status of personal monitoring using thermoluminescent(TL), optically stimulated luminescent(osl), and radiophotoluminescent (rpl) dosimeters. International Journal of Luminescence and Applications 3(1):6-10.

Bhatt, B.C., and M.S. Kulkarni. 2014. Thermoluminescent phosphors for radiation dosimetry. Chapter in Defect and Diffusion Forum 347: 179-227.

Bhatt, C.R.,A.Widmark, S.L.Shrestha, T.Khanal, and B.Ween.2012. Occupational radiation exposure in health care facilities. Kathmandu Univ Med J.39(3):48-51.

Division of radiological protection.1986. Development of a thermoluminescent personnel monitoring system. Bhava Atomic Research Centre (BARC), India.

Furetta, C., 2003. Handbook of thermoluminescence. World Scientific Publishing Co.Pvt.Ltd., Singapore.

Gautam, R.P., and J.N.Prasain. 2011. Current situation of occupational safety and health in Nepal (a study report).GEFONT, Kathmandu, Nepal.

Government of Nepal. 2007. National Nuclear Policy.

Government of Nepal. 2015. Nuclear Materials Regulatory Directive.

Khanal, O.B., D.Thapa, B.R. Shah, D. D.Mulmi, A. Shah, and S.K.Aryal. 2014. Study of the exposure rate from the patients injected with a 
radiopharmaceutical. International Journal of Applied Sciences and Biotechnology, 2(3): 336341.

International Atomic Energy Agency (IAEA). 2015. Preparedness and response for a nuclear or radiological emergency. General Safety Requirements, No. GSR Part 7. IAEA, Vienna.

International Atomic Energy Agency (IAEA). 2010. Radiation Biology: A handbook for teachers and students. Training Course Series 42. IAEA, Vienna.

International Atomic Energy Agency (IAEA). 2014. Radiation Protection and Safety of Radiation Sources: International Basic Safety Standards Interim Edition. General Safety Requirements, No. GSR, part 3. IAEA, Vienna.

International Atomic Energy Agency (IAEA).2011. Radiation Safety in Industrial Radiography. Specific Safety Guide no.11.IAEA, Vienna.

International Commission on Radiological Protection (ICRP). 2007. The 2007 recommendations of the International Commission on Radiological Protection, ICRP Publication 103. Volume 37 Nos 2-4.

Lakshmanan, A.R., M.T. Jose, and O. Annalakshmi.
2008. High Sensitive $\mathrm{CaSO}_{4}$ : Dythermoluminiscent phosphor synthesis by co-precipitation technique. Radiation Protection Dosimetry 132(1): 42-50.

Nucleonix System Private Limited. 2013. Instruction Manual: Semi-Automatic TLD Badge Reader Type: TL1010A. Nucleonics System Private Limited, India.

Rizk, C., S. Long, H.B. Okyar, S. Baradaran, E.Al Fares, J.K. Sangau, and B. R. Shah. 2019. Results of the Joint IAEA/ARPANSA Intercomparison Exercise on Whole Body Dosemeters for Photons in Asia and the Pacific Region. Radiation Protection Dosimetry, 182:1-8.

Srivastava, K., G. Varadharajan, M.P. Punekar, P. Ayappanl., and M. P. Chougaonkar. 2011. Adequacy of annealing duration in reducing the background counts of personnel monitoring TLD cards: A study. Publication of Indian Association for Radiation and Protection (IARP). 34(1): 23-25.

Srivastava, K., A.K. Bakshi, M.P. Punekar, D.H. Kolambe, P. Ratna, and D. Datta. 2016. Overview of the quality assurance program implemented for TLD based individual monitoring in India. Radiation Protection Dosimetry 174 (2): 175-184. 